\title{
Engine performance and combustion characteristics of a direct injection compression ignition engine fueled waste cooking oil synthetic diesel
}

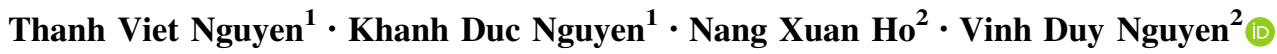

Received: 18 May 2019/Revised: 22 April 2020/Accepted: 11 May 2020/Published online: 26 May 2020

(C) The Author(s) 2020

\begin{abstract}
Biodiesels produced from various feedstocks have been considered as alternative fuels used in internal combustion engines without major modifications. This research focuses on producing biodiesel from waste cooking oil (WCOSD) by the catalytic cracking method using $\mathrm{MgO}$ as the catalyst and comparing the engine operating characteristics of the test engine when using WCOSD and traditional diesel (CD) as test fuels. As a result, the brake power of the test engine fueled WCOSD, and traditional diesel is similar. However, the engine fuel consumption in the case of using WCOSD is slight increases in some operating conditions. Also, the nitrogen oxides emissions of the test engine fueled WCOSD are higher than those of CD at all tested conditions. The trend is opposite for hydrocarbon emission as the HC emission of the engine fueled by WCOSD reduces $26.3 \%$ on average. The smoke emission of the test engine in case of using WCOSD is lower 17\% on average than that of CD. However, the carbon monoxide emissions are lower at the low and medium loads and higher at the full loads. These results show that the new biodiesel has the same characteristics as those of commercial biodiesel and can be used as fuel for diesel engines.
\end{abstract}

Keywords Feedstock · Waste cooking oil $\cdot$ Engine characteristics $\cdot$ Exhaust missions $\cdot$ Ignition timing $\cdot$ Fuel consumption

\section{Introduction}

Diesel engines are used in transportation, power plants, construction, and rural agricultural and industrial activities; consequently, it has led to increasing in demand for petroleum-based diesel (Boggavarapu and Ravikrishna 2013), while fossil fuel reserves in the world are limited. Also, the problems of air pollution and global warming have been becoming even more critical than ever. Scientists worldwide have been working diligently to find out renewable, carbon-neutral, and environmentally friendly fuels to

Vinh Duy Nguyen

vinh.nguyenduy@phenikaa-uni.edu.vn

1 Department of Internal Combustion Engine, School of Transportation Engineering, Hanoi University of Science and Technology, Hanoi, Viet Nam

2 Faculty of Vehicle and Energy Engineering, Phenikaa University, Yen Nghia, Ha-Dong District, Hanoi, Viet Nam replace the petroleum-based diesel. As shown in previous reports (Rajasekar et al. 2010; Altin et al. 2001; Fukuda et al. 2001; Sayin and Canakci 2009; Han et al. 2010; Kannan et al. 2011; Macor et al. 2011), biodiesel fuel, oxygenated, biodegradable, non-toxic, and environmentally friendly fuel, has been considered as a very promising alternative fuel to replace traditional diesel fuel.

Biodiesel produced from various resources such as rapeseed, soybean, cottonseed oil, palm oil, jojoba oil, sunflower has been used in internal combustion engines without major modifications as reported by Muralidharan and Vasudevan (2011). Saravanan et al. (2010) also investigated the combustion characteristics of a heavy commercial vehicle compression-ignition engine fueled with crude rice bran oil methyl ester (CRBME). Consequently, when comparing CRBME with diesel fuel they found that the delay period was shorter by about $15 \%$, the peak pressure was slightly lower, the maximum heat release rate and the thermal brake efficiency were $34 \%$ and 
$8 \%$ lower, respectively; meanwhile, the brake specific energy consumption (BSEC) was about $18 \%$ higher. Qi et al. (2009) tested biodiesel produced from crude soybean oil on a single-cylinder, naturally aspirated, and direct injection diesel engine. They observed that the peak cylinder pressure of biodiesel was higher at lower engine loads and identical at higher engine loads, and combustion started earlier at all engine loads. They also showed that the power output of the biodiesel engine was almost the same as that of a diesel engine under-speed characteristic at full load. Under almost all engine speed ranges, the BSEC of biodiesel was closer than that of diesel. In another research, Huang et al. (2010) investigated two different biodiesels produced from pistachio and jatropha to compare performance and emission characteristics when they were used for a diesel engine. They found that exhaust emissions could be reduced by using biodiesel. Indeed, carbon monoxide (CO) and hydrocarbon ( $\mathrm{HC})$ emissions were reduced at high engine loads. Moreover, nitrogen oxides $\left(\mathrm{NO}_{x}\right)$ and smoke emissions were also reduced dramatically at different engine loads. Also, the engine performance and emissions run by pistache were very similar to those run by jatropha biodiesel.

Compared to petroleum-based diesel, the high cost and most of the biodiesels produced from edible oils such as rapeseed oil, sunflower oil, and palm oil are major barriers to commercialize. Approximately $70 \%-80 \%$ of the total biodiesel production cost from the raw material cost (Meng e al. 2008). Moreover, the use of these oils would cause the competition of farming land for food and fuel supply, which results in oil and food price inflation (Huang et al. 2010). Therefore, the use of low-cost, non-edible feedstock such as waste cooking oil is expected to be competitive in price with petroleum diesel and to ensure food security in the world. Furthermore, the use of waste cooking oil as an engine fuel also contributes to reducing environmental problems due to the waste-oil disposal process.

In their experiment with waste palm oil (WPOME) and canola oil methyl esters (COME), Necati et al. (2009) observed that the maximum engine torque slightly dropped. At the same time, the BSFC increased in comparison with those of the petroleum-based diesel fuel (PBDF). The maximum brake torques for PBDF, WPOME, and COME at $1500 \mathrm{rpm}$ corresponding to the full load condition were $328.69,320.24$, and $319.80 \mathrm{~N} \mathrm{~m}$, respectively. The BSFC of WPOME and COME increased by $7.48 \%$ and $6.18 \%$, while thermal brake efficiency reduced by $1.42 \%$ and $0.12 \%$, respectively. In another research, Muralidharan and Vasudevan (2011) investigated the effects of compression ratio on characteristics of a variable compression ratio engine using methyl esters of waste cooking oil and diesel blends. As a result, the thermal brake efficiency for B40 significantly improved at a compression ratio of 21 in comparison to that of standard diesel. The specific fuel consumption of the blend B40 at the compression ratio of 21 was $0.259 \mathrm{~kg} / \mathrm{kWh}$, whereas it was $0.314 \mathrm{~kg} / \mathrm{kWh}$ in the case of standard diesel.

Although there have been many investigations, as listed above, in the useability of waste cooking oil on compression-ignition engines, these investigations used biodiesels produced from waste cooking oil throughout the transesterification reaction directly waste cooking oil to fuel for the engine. Also, these studies only focused on testing at some operating engine points, such as speed characteristics at full load or load characteristic at rated engine speed. For these reasons, the objectives of this study are to produce biodiesel from waste cooking oil and investigate the compression-ignition engine performance and its combustion characteristics fueled by waste cooking oil synthetic diesel (WCOSD) corresponding to all main operating engine points.

\section{Catalytic cracking process of waste cooking oil}

Waste Cooking Oil (WCO) was collected from local restaurants in Hanoi city in Vietnam. Catalytic cracking manipulations were carried out at $450{ }^{\circ} \mathrm{C}$ in a rounded bottom one-liter batch reactor in the presence of $5 \mathrm{wt} \%$ $\mathrm{MgO}$ catalyst, as showed in Fig. 1. For each experiment, $500 \mathrm{~g}$ of sample and $25 \mathrm{~g}$ of $\mathrm{MgO}$ were placed in the reactor. The reactor temperature was gradually raised to $450{ }^{\circ} \mathrm{C}$ by an electric furnace at heating rates of $10^{\circ} \mathrm{C} / \mathrm{min}$ and kept at isothermal condition until no more vapour. We use an AC electrical source ( $220 \mathrm{~V}$ and $4 \mathrm{~A}$ ) to supply for the electric furnace. It took $40 \mathrm{~min}$ to reach an operating temperature of $450{ }^{\circ} \mathrm{C}$, and then this temperature is continuously controlled by turn $\mathrm{ON}$ and OFF the electrical source. We got the first litre of biodiesel after $40 \mathrm{~min}$, and then it took 40 min to get one more litre of the biodiesel. The average electrical cost to produce $1 \mathrm{~L}$ of biodiesel is

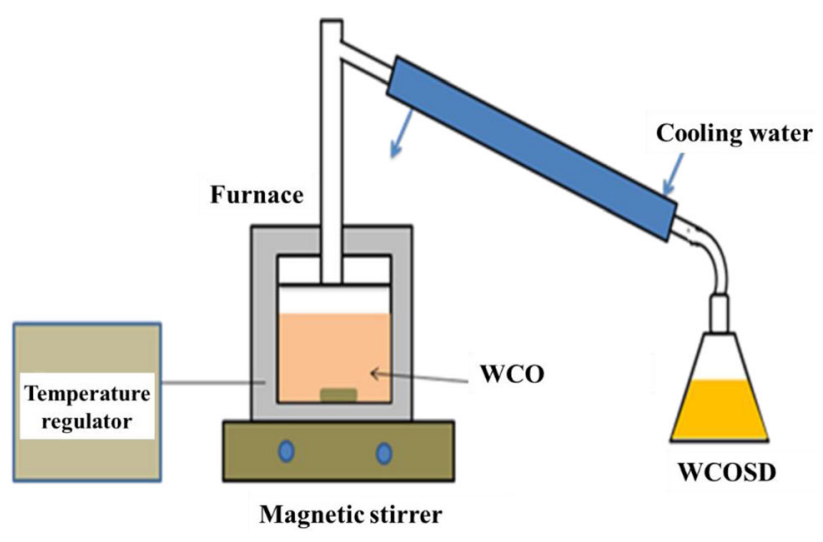

Fig. 1 Principle diagram of the WCO cracking system 
approximately a quarter of the price of diesel on the market. Also, by using waste cooking oil as raw material, it will reduce the cost of paying for disposing of waste cooking oil. The vapour was allowed to pass through a condenser to collect WCOSD in the liquid phase.

In our production process, the catalyst only was added to the reactor after the temperature of the reactor reached the operating temperature of $450{ }^{\circ} \mathrm{C}$. The valve connecting the reactor and condenser is opened $20 \mathrm{~min}$ after the catalyst added to the reactor. Therefore, the temperature for catalytic cracking always controlled at approximately $450{ }^{\circ} \mathrm{C}$. The cracked products compose of naphtha (approximately $2.9 \%$ ), kerosene (approximately 8.7\%), diesel $(67 \%$ including), and residue $(21.4 \%)$. It needed approximately 1.5 L of waste cooking oil to produce $1 \mathrm{~L}$ of biodiesel. We repeated the production process five times, and observed that the yield and composition of the cracking product were quite stable as the raw materials were the same. One disadvantage of using fixed-bed of catalysts is that it might be necessary to change the catalysts quite often as byproducts can contaminate on the surface of the fixed-bed, hence reducing the contact area between the vapours and the catalysts and affecting the quality of the biodiesel. In addition, it might be more challenging to change catalyst fixed in the heated bed, and the product prices might be increased due cost for preparing catalyst beds. The catalyst was mixed to the raw materials in the reactor so that the effect of a catalyst on the cracking reactions was maintained stable. Moreover, changing the catalyst was pure as the catalyst was taken out together with byproducts. In our experiment, we have prepared $20 \mathrm{~L}$ of biodiesel for all tests, performance test, and fuel property tests. Although the volume of the reactor is approximately $1 \mathrm{~L}$, our production process is continuous. When the biodiesel was taken out from the condenser, the raw materials and catalyst were added to the reactor at the same time.

The fuel properties of WCOSD products were evaluated to compare to regular diesel fuel using ASTM methods. Cetane number, density, kinematic viscosity, flash point, carbon residue, ash, sulfur and the calorific value of WCOSD were characterized. Cetane number was determined by comparing its combustion characteristics in a test engine with those for blends of reference fuels of known cetane number under standard operating conditions (ASTM
D-613). A digital density analyzer was used to measure the sample at $25^{\circ} \mathrm{C}$ temperature (ASTM D-4052). Kinematic viscosity was determined using a U-tube viscometer (ASTM D-445). Flashpoint of WCOSD was determined by filling the test cup with WCOSD to the filling mark inside of the test cup, and the lighted test flame was passed along the circumference of the cup (ASTM D-92). The calorific values of the samples were determined using a bomb calorimeter (ASTM D-240). Carbon residue was calculated through the amount of carbon residue left after evaporation and pyrolysis of the sample (ASTM D-189). Ash was calculated by igniting and burning samples until only ash and carbon remain (ASTM D-482). The sulfur content was determined using an energy-dispersive X-ray fluorescence analyzer (ASTM D-4294).

\section{Testing equipment, experiment setup, and test procedure}

\subsection{Test fuels and engine used in the experiment}

In this study, the waste cooking oil synthetic diesel successfully produced from waste cooking oil in this research was used and compared with conventional diesel fuel when they were used to run on an internal combustion engine. The physical and chemical properties of WCOSD and CD fuels are shown in Table 1. The test engine is a four-stroke, single-cylinder, water-cooled, naturally aspirated, direct injection diesel engine.

\subsection{Test setup and experimental procedure}

Figure 2 shows the schematic diagram of engine testbed, including a test engine, chassis dynamometer, exhaust gas analyzer device, control unit, fuel consumption device, airflow measurement instrument, and temperature sensors. To conduct the specific engine speed, the experiments were conducted with the single-cylinder diesel engine corresponding to various engine speeds. In the experiment, the engine was coupled with a $40 \mathrm{~kW}$ regenerative dynamometer. The cylinder pressures were recorded by a high-speed data acquisition system, including two high accuracies of piezoelectric pressure transducers, a crank

Table 1 Physical and chemical properties of tested fuels

\begin{tabular}{lccccccc}
\hline Properties & \multicolumn{2}{l}{ Elememt composition $(\%)$} & Density at $15{ }^{\circ} \mathrm{C}\left(\mathrm{kg} / \mathrm{m}^{3}\right)$ & Viscosity at $40{ }^{\circ} \mathrm{C}\left(\mathrm{mm}^{2} / \mathrm{s}\right)$ & Heating value $(\mathrm{MJ} / \mathrm{kg})$ & Flash point $\left({ }^{\circ} \mathrm{C}\right)$ \\
\cline { 2 - 5 } & $\mathrm{C}$ & $\mathrm{H}$ & $\mathrm{N}$ & & & & \\
\hline WOBD & 77.14 & 14.60 & 0.078 & 820.29 & 2.92 & 44.484 & 93.5 \\
CD & 81.17 & 15.29 & 0.067 & 827.49 & 3.74 & 44.864 & 81.5 \\
Method & - & - & - & ASTM D1298 & ASTM D445 & ASTM 04-5865 & ASTM D92 \\
\hline
\end{tabular}




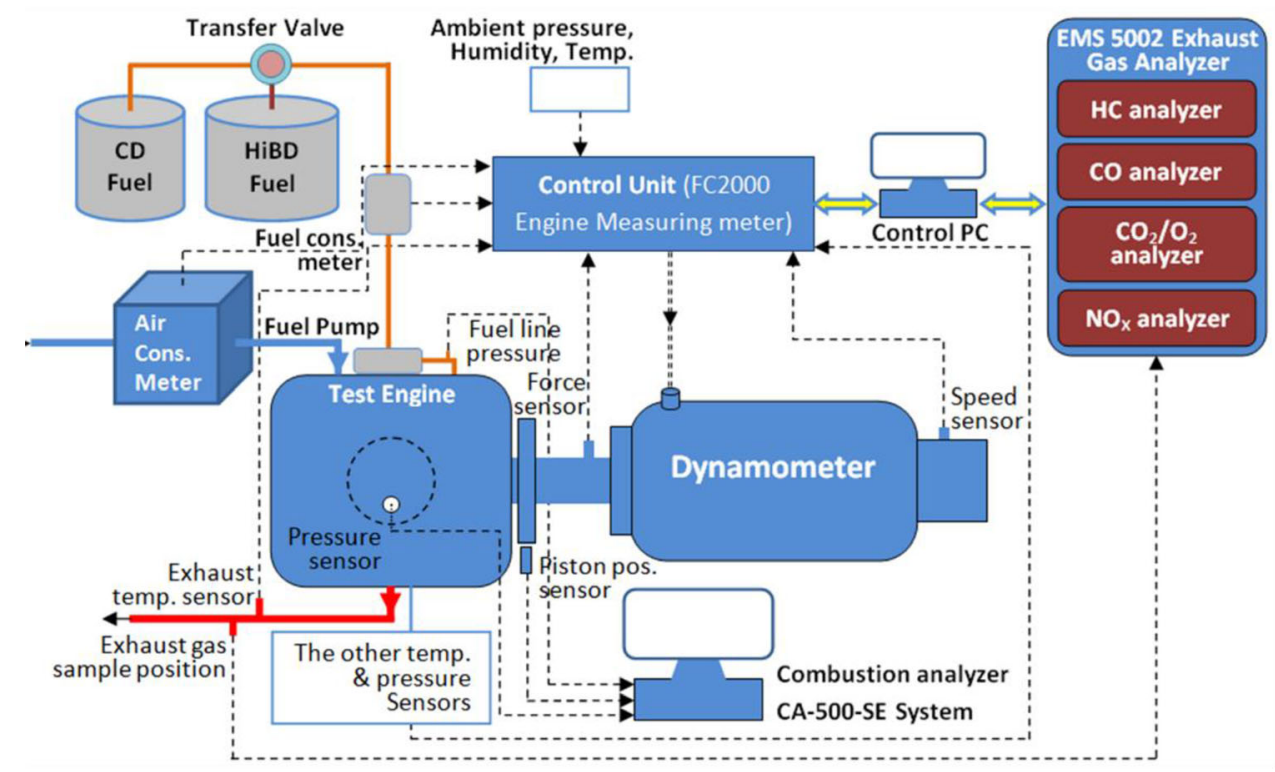

Fig. 2 Schematic diagram of the engine testbed and completed engine testbed in the experiment

angle encoder, and a combustion analyzer device. The fuel consumption device determined the fuel rate supplied for the test engine. In order to measure the airflow rate, the air consumption meter was set up on the intake manifold of the test engine. Also, six different digital thermocouples were set up to measure the exhaust gas, engine oil, coolant inlet and outlet, fuel, and air inlet temperature. Furthermore, the ambient temperature, air density, and relative humidity also were recorded. To control the engine and dynamometer, the control system was used to; consequently, it collected signals from measuring equipment and displayed measuring results. The exhaust emissions of the tests, including $\mathrm{CO}, \mathrm{CO}_{2}$, Hydrocarbon (HC), $\mathrm{O}_{2}$ and $\mathrm{NO}_{x}$ were measured by an exhaust gas analyzer device manufactured for measuring internal combustion engine emissions. The characteristics of the measuring instruments and the gas analyzers are presented in Table 2 .

\section{Results and discussions}

\subsection{Comparison of properties between WCOSD and diesel fuels}

The properties of WCOSD are showed in Table 3 and compared to the standard Euro $\mathrm{V}$ specification of diesel fuel. The cetane number of WCOSD was slightly lower than diesel fuel due to the content of unsaturated components; that could inhibit the combustion of the fuel in the engine. Another disadvantage was the low calorific value of WCOSD because of the high content of oxygenates compounds (Wako et al. 2018), which had a worse effect
Table 2 Accuracies of the measuring instruments and the gas analyzers

\begin{tabular}{lll}
\hline Item & Technical parameters & \\
\hline Model of equipment & EMS 5002 & \\
Power (VDC) & $10-16$ & \\
Ranges & $\mathrm{NO}(\mathrm{ppm})$ & $0-5000$ \\
& $\mathrm{O}_{2}(\%)$ & $0-25$ \\
& $\mathrm{CO}_{2}(\%)$ & $0-20$ \\
& $\mathrm{CO}(\%)$ & $0-10$ \\
& $\mathrm{HC}(\mathrm{ppm})$ & $0-20000$ \\
Display resolution & $\mathrm{NO}(\mathrm{ppm})$ & 1 \\
& $\mathrm{O}_{2}(\% \mathrm{vol})$ & 0.01 \\
& $\mathrm{CO}(\% \mathrm{vol})$ & 0.1 \\
& $\mathrm{CO}(\% \mathrm{vol})$ & 0.01 \\
& $\mathrm{HC}(\mathrm{ppm})$ & 1 \\
Accuracy & $\mathrm{NO}(\mathrm{ppm})$ & 25 \\
& $\mathrm{O}_{2}(\%)$ & 0.1 \\
& $\mathrm{CO}_{2}(\%)$ & 0.3 \\
& $\mathrm{CO}(\%)$ & 0.06 \\
& $\mathrm{HC}(\mathrm{ppm})$ & 4 \\
\hline
\end{tabular}

on the performance of the engine. The viscosity of the biodiesel was slightly higher than that of diesel fuel, which caused worse atomization in the engine and probably reduced the combustion efficiency due to the formation of carbon deposits contaminating in the combustion chamber. However, WCOSD had some advantages such as completely free of sulfur, free of ash content, and carbon residue as compared to diesel fuel. The properties of 
Table 3 Fuel properties of WCOSD compared to EN 590:2009 standard specifications of diesel fuel

\begin{tabular}{lll}
\hline Property & WCOSD & EN 590:2009 standard \\
\hline Cetane number & 47.7 & $\geq 51$ \\
Densityat $15{ }^{\circ} \mathrm{C}\left(\mathrm{g} / \mathrm{cm}^{3}\right)$ & 0.86 & $0.820-0.845$ \\
Kinematic viscosity at $40{ }^{\circ} \mathrm{C}(\mathrm{cSt})$ & 6.20 & $2.0-4.5$ \\
Flashpoint $\left({ }^{\circ} \mathrm{C}\right)$ & 92 & $\geq 55$ \\
Ash content $(\mathrm{wt} \%)$ & $\mathrm{Nil}$ & $\leq 0.01$ \\
Carbon residue $(\mathrm{wt} \%)$ & $\mathrm{Nil}$ & $\leq 0.3$ \\
Total sulfur $(\mathrm{ppm})$ & $<3$ & $\leq 10$ \\
Calorific value $(\mathrm{kJ} / \mathrm{kg})$ & 41.2 & -
\end{tabular}

WCOSD were found to be closer to regular diesel fuel; hence regular diesel was used as a comparison fuel in the engine performance test.

\subsection{Comparison of engine performance characteristics}

Figure 3 a shows a comparison of the engine performance at different engine speeds and full load conditions when WCOSD and CD were utilized as test fuels. Generally, the engine performance was entirely consistent over the engine speed range from 1400 to $2100 \mathrm{rpm}$. Indeed, when CD used as a fuel, the brake powers at engine operating speeds of $1400 \mathrm{rpm}$ and $1700 \mathrm{rpm}$ were, respectively, $2.90 \%$, $2.43 \%$ higher in comparison with those of WCOSD. Also, the fuel consumption characteristics of the test engine in case of using WCOSD were higher than those in the case of using $\mathrm{CD}$, as shown in Fig. 3b, which probably resulted from WCOSD lower calorific value, as shown in Table 1. Moreover, the density and kinematic viscosity of diesel

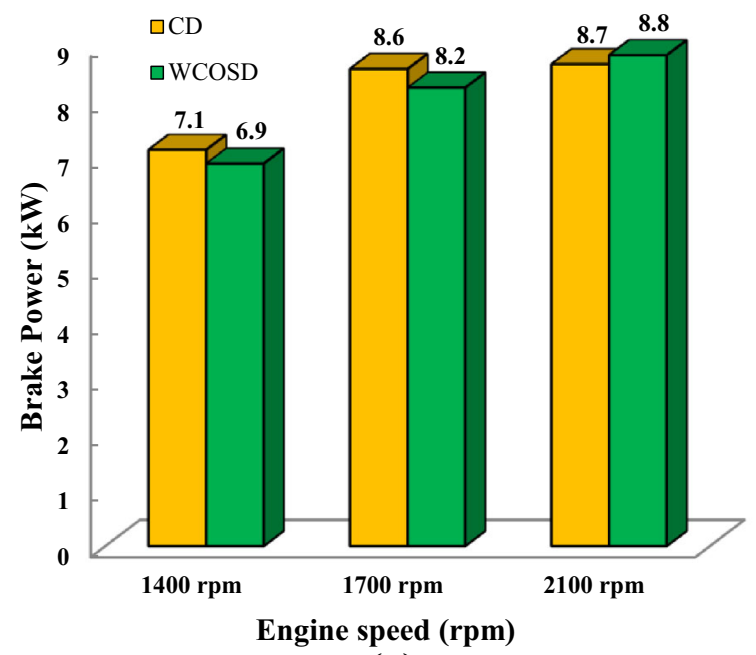

(a) were higher than those of WCOSD, which also contributed to a reduction of the engine power because of an increase in the friction loss. However, as shown in Fig. 3a at high speed, the engine power in the case of using WCOSD was slightly higher than that of $\mathrm{CD}$, which resulted from the effect of viscosity. Since the WCOSD viscosity was smaller than the CD viscosity, the mixture of WCOSD and air became more advantageous compared to that of $\mathrm{CD}$, especially in case of high engine speeds as the duration for mixture formation was limited.

Figure 4 presents the variation of brake specific fuel consumption (BSFC) corresponding to each constant engine speed of 1400, 1700 and $2100 \mathrm{rpm}$ and the engine torque ranging from 0 to $50 \mathrm{~N}$ m when the test engine fueled with WCOSD and CD. The results showed that the BSFC of WCOSD was always higher than that of CD at every engine operation point. At the same operating conditions, the highest difference in BSFC between the two fuels is $19 \%$ at the operating point of $1700 \mathrm{rpm}$ engine speed and $25 \%$ load. Meanwhile, the BSFC of the two fuels

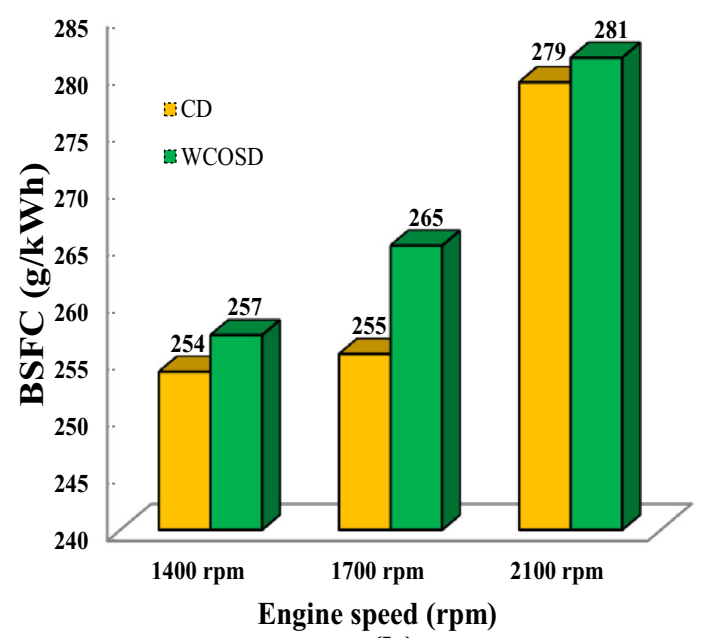

(b)

Fig. 3 Comparison of engine characteristics a engine power and $\mathbf{b}$ fuel consumption 

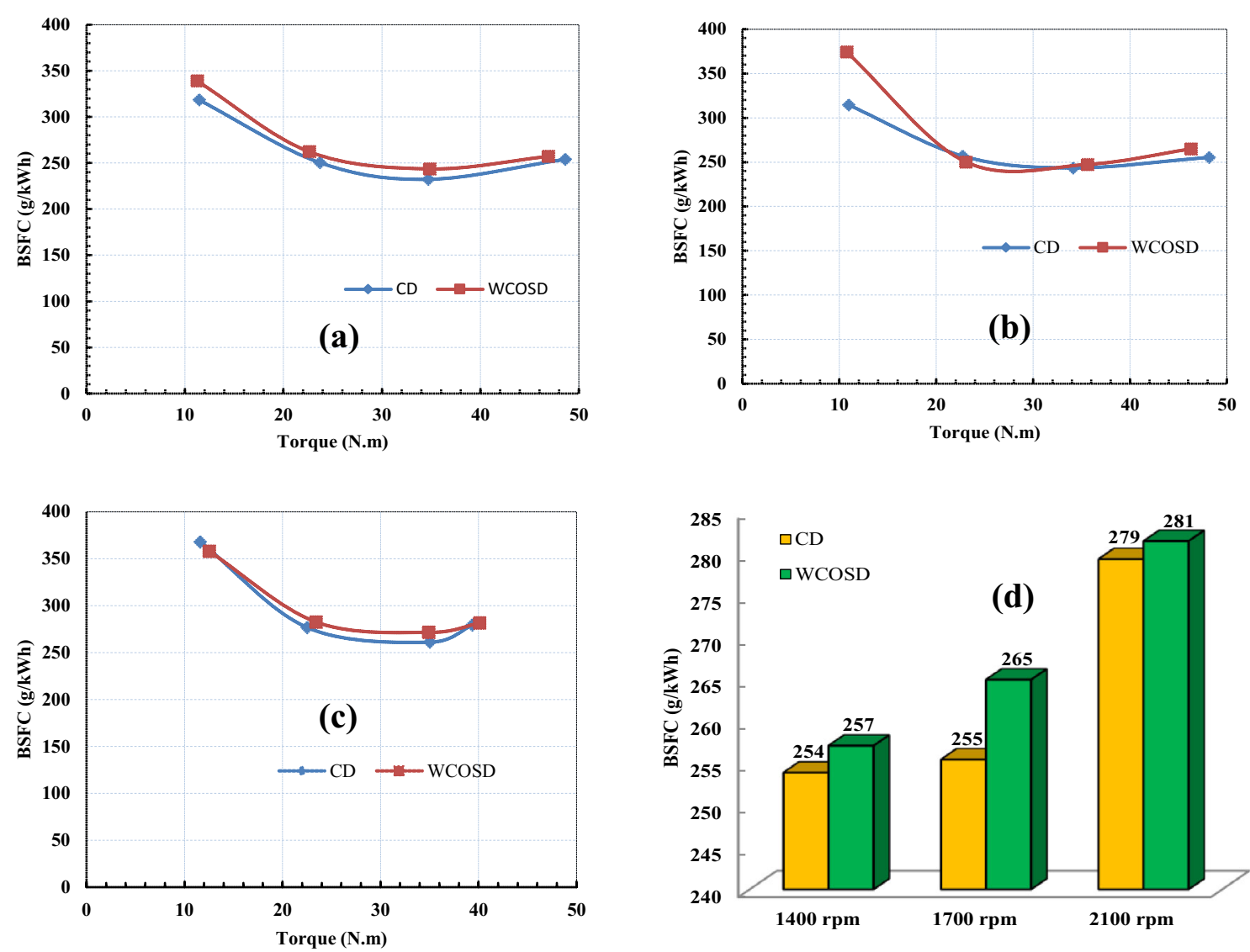

Fig. 4 Brake specific consumption of the test engine fueled CD and WOCSD at a $1400 \mathrm{rpm}$, b $1700 \mathrm{rpm}$, c $2100 \mathrm{rpm}$, and d full load

was similar at $75 \%$ of the maximum torque. This trend is the same as those concluded from Meng et al. (2008), Necati et al. (2009), Hirkude and Padalkar (2012), Zhu et al. (2011), Di et al. (2009) and Necati and Canakci (2010) investigating two types of biodiesel derived from waste palm oil and canola oil. In order to maintain the same power output, a higher amount of WCOSD should be supplied, as suggested by Muralidharan and Vasudevan (2011), Buyukkaya (2010), Hirkude and Padalkar (2012), Zhu et al. (2011) and Di et al. (2009) due to the lower calorific value of WCOSD compared to CD.

The lower output power and higher fuel consumption of WCOSD led to the lower brake thermal efficiency (BTE) in comparison to that of $\mathrm{CD}$ at all engine operating conditions, as depicted in Fig. 5. For example, at the same operating condition of $1400 \mathrm{rpm}$ and $70 \%$ of load condition, the BTE of the engine fueled with $\mathrm{CD}$ reached the highest value of $38.3 \%$ while that fueled with WCOSD was $36.6 \%$. Notably, at the operating point of $1400 \mathrm{rpm}$ and $25 \%$ of load, the difference in BTE between WCOSD and $\mathrm{CD}$ was as high as approximately $21 \%$. The second reason for these results can be explained by the higher viscosity and weak volatility of WCOSD, resulting in more poor atomization and combustion characteristics, as described in results concluded in Hirkude and Padalkar (2012) and Necati and Canakci (2010).

\subsection{Comparison of combustion characteristics}

Combustion characteristics of WCOSD and CD in this research were investigated based on means of in-cylinder pressure and ignition delay. To analyze the combustion process, the in-cylinder pressure and fuel line pressure data of 200 cycles with a $0.4^{\circ}$ resolution of crank angle were measured and analyzed. Figure $6 a$ shows the variation of in-cylinder pressure versus crank angle when the test engine fueled with CD and WCOSD fuels at a speed of 1400 and various engine loads of 11,23 , and $35 \mathrm{~N} \mathrm{~m}$. The observed in-cylinder pressure peaks for the engine running with WCOSD were lower than those of CD by $0.43,0.32$, and 0.74 bar at 11,23 , and $35 \mathrm{~N}$ m, respectively. However, the in-cylinder pressures were quite similar in the areas far from the top dead center. The lower in in-cylinder pressure peaks can result from the improper mixing of WCOSD with air at low engine temperature due to its characteristics.

Figure 6d compares the ignition delay, which is defined as the time interval between the start of injection and the start of combustion, of the test engine fueled by WCOSD 

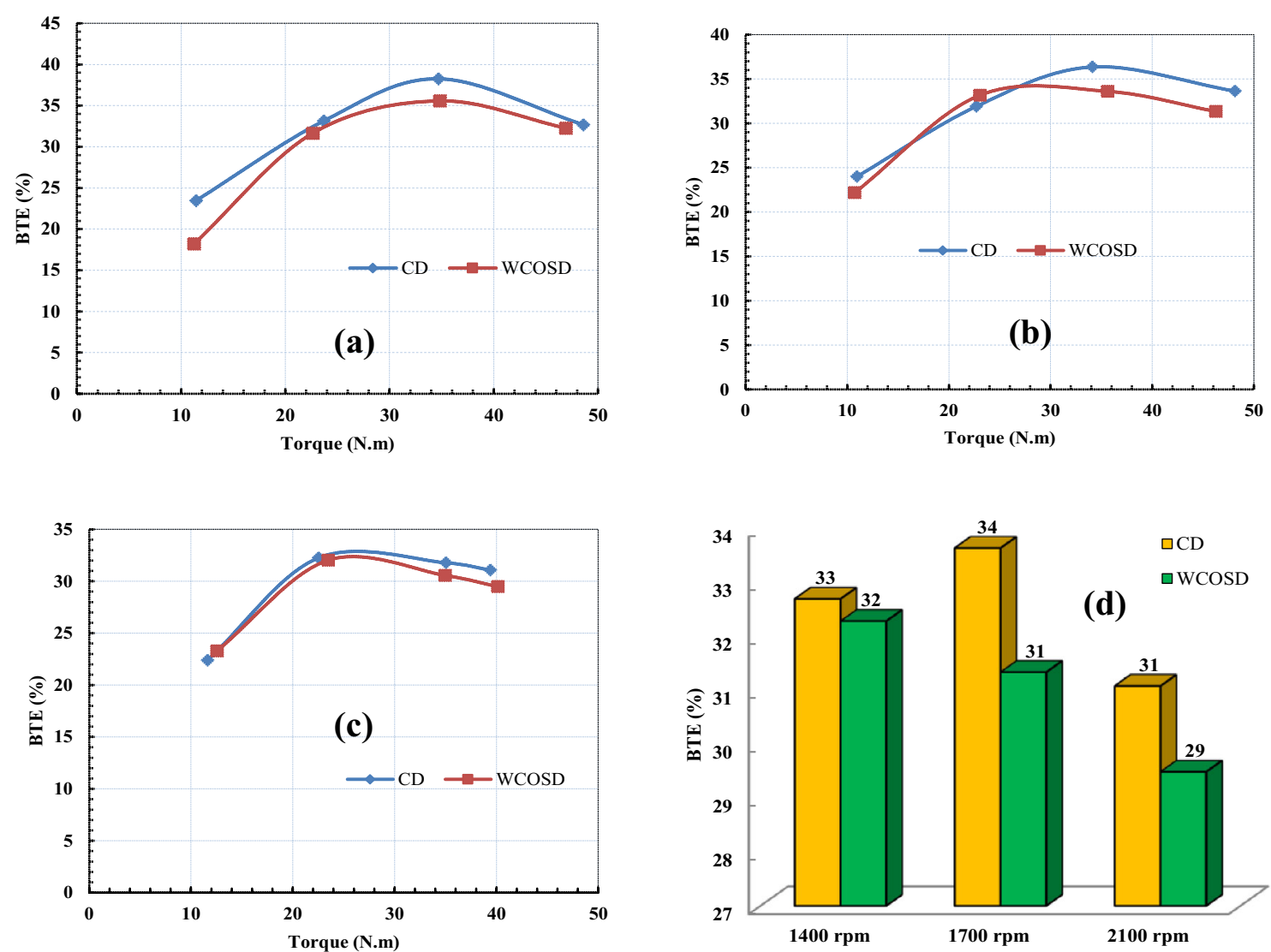

Fig. 5 Brake thermal efficiency of the test engine fueled CD and WOCSD at a $1400 \mathrm{rpm}, \mathbf{b} 1700 \mathrm{rpm}$, c $2100 \mathrm{rpm}$ and d full load

and $\mathrm{CD}$ at different operating conditions. It can be observed that the ignition of the WCOSD started earlier than that of $\mathrm{CD}$ by from 0.4 to $0.8^{\circ} \mathrm{CA}$. The advanced ignition start of WCOSD results from the physical properties of WCOSD (Tesfa et al. 2013). Also, the ignition delay for WCOSD was shorter than that for CD at low and medium load, whereas the opposite result was found at high loads, as shown in Fig. 6d.

\subsection{The compassion of exhaust emissions}

\subsubsection{Comparison of carbon monoxide emissions}

Figure 7 shows the experimental results of carbon monoxide (CO) emissions from the test engine fueled WCOSD and CD. It can be seen that the trends of CO emissions from the engine fueled with the two fuels were similar to each other. The $\mathrm{CO}$ emissions were low at the low and medium loads and high at the full loads. The main reason for this phenomenon is that the mixtures at full load were more abundant than those at low and medium loads, resulting in a lack of oxygen in the combustion process at full load conditions. At full load conditions, the $\mathrm{CO}$ emissions of the engine fueled with $\mathrm{CD}$ were higher than that with WCOSD, 34.85\% higher at $1400 \mathrm{rpm}$, and $58.33 \%$ higher at $1700 \mathrm{rpm}$. However, the trend was opposite at high engine speed. At $2100 \mathrm{rpm}$, when the test engine fueled with $\mathrm{CD}$, the $\mathrm{CO}$ emissions were $45.9 \%$ lower than that fueled with WCOSD.

\subsubsection{Comparison of nitrogen oxides emissions}

Figure 8 shows the variation of nitrogen oxides $\left(\mathrm{NO}_{x}\right)$ emissions versus engine speeds and loads. At the same operating conditions, the $\mathrm{NO}_{x}$ emissions produced by WCOSD were higher in comparison to that of CD. The highest $\mathrm{NO}_{x}$ emissions produced by WCOSD were 1165 , 1140 , and 846 at 1400, 1700, and $2100 \mathrm{rpm}$, respectively, whereas those of CD were respectively 1150, 1023, and $833 \mathrm{ppm}$. The higher $\mathrm{NO}_{x}$ emission of the test engine in case of using WCOSD might result from the provision of the oxygen content in WCOSD, which probably contributed to the formation of $\mathrm{NO}_{x}$. Another factor that caused the increase of $\mathrm{NO}_{x}$ emission is the higher peak temperature during combustion for WCOSD compared to diesel. 

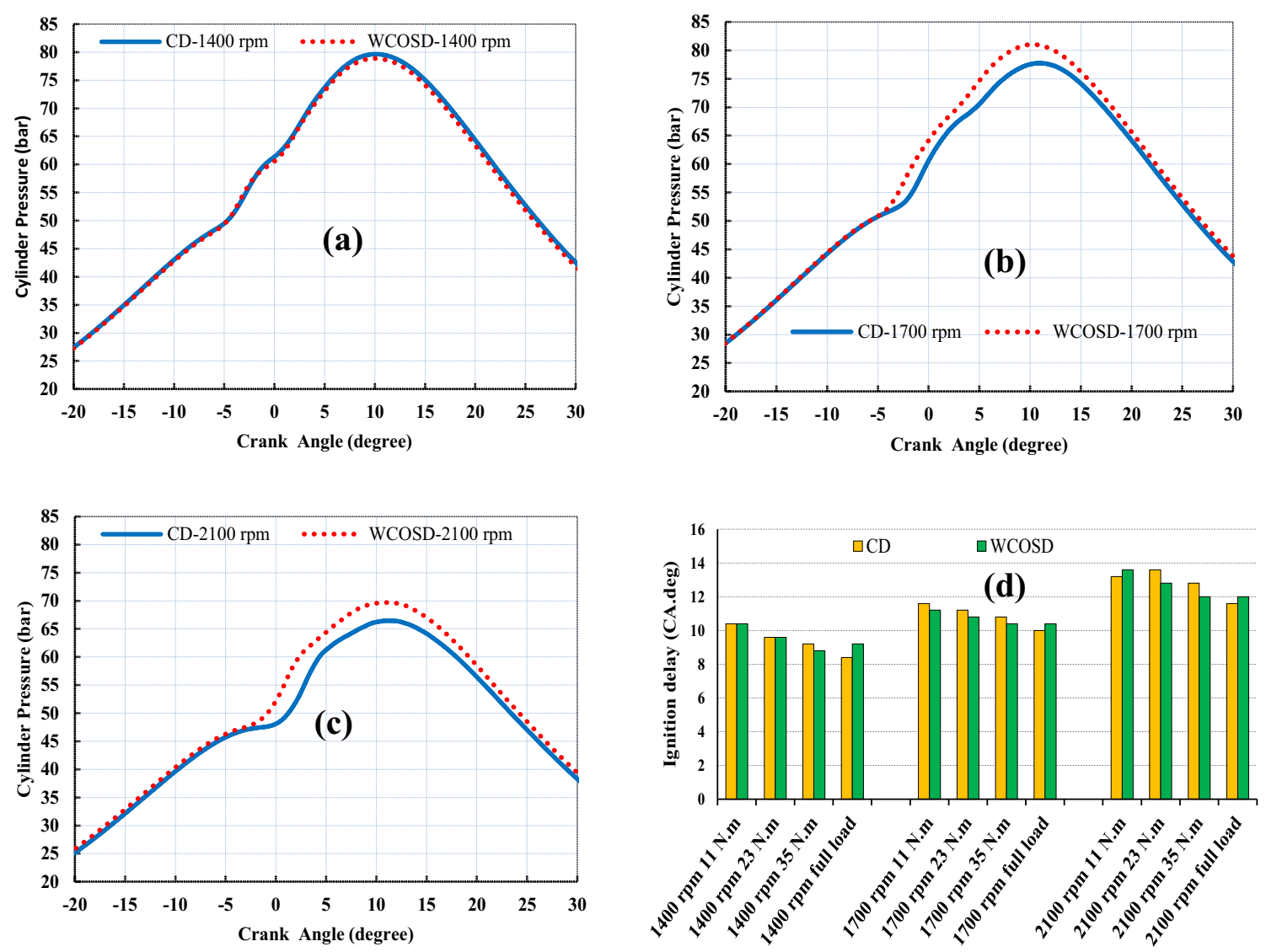

Fig. 6 Variation of in-cylinder pressure of the test engine fueled CD and WOCSD at a $1400 \mathrm{rpm}, \mathbf{b} 1700 \mathrm{rpm}, \mathbf{c} 2100 \mathrm{rpm}$, and d ignition delay at different operating conditions
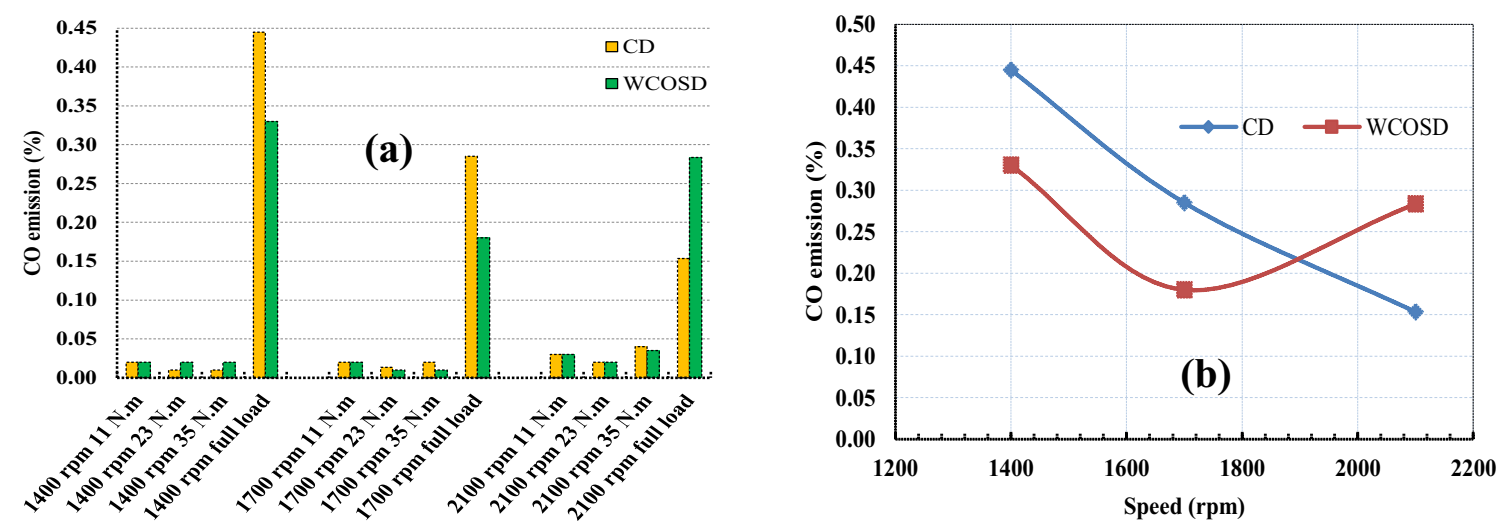

Fig. 7 Carbon monoxide emissions of the test engine fueled CD and WOCSD at a $1400 \mathrm{rpm}, 1700 \mathrm{rpm}, 2100 \mathrm{rpm}$ and $\mathbf{b}$ full load

\subsubsection{Comparison of hydrocarbon emissions}

The hydrocarbon (HC) emissions of the test engine running on both WCOSD and CD were found to be very low at all engine operating conditions. The variations of $\mathrm{HC}$ emissions between two types of fuels at the 12 operating conditions tested in this study is shown in Fig. 9. It can be seen that under most operating conditions, the $\mathrm{HC}$ emissions of test engines running on WCOSD were lower than those of
CD. The $\mathrm{HC}$ emission of the engine fueled by WCOSD reduced by $26.3 \%$ on average compared to that of the engine fueled by $\mathrm{CD}$. From these results, we can conclude that the use of WCOSD generally resulted in lower HC emissions due to its clearer combustion. Besides, at full load conditions, when the engine speed increased from 1400 to $2100 \mathrm{rpm}$, the $\mathrm{HC}$ emission of an engine running on two types of fuel significantly reduced due to the higher temperatures leading to better atomization and volatility. 

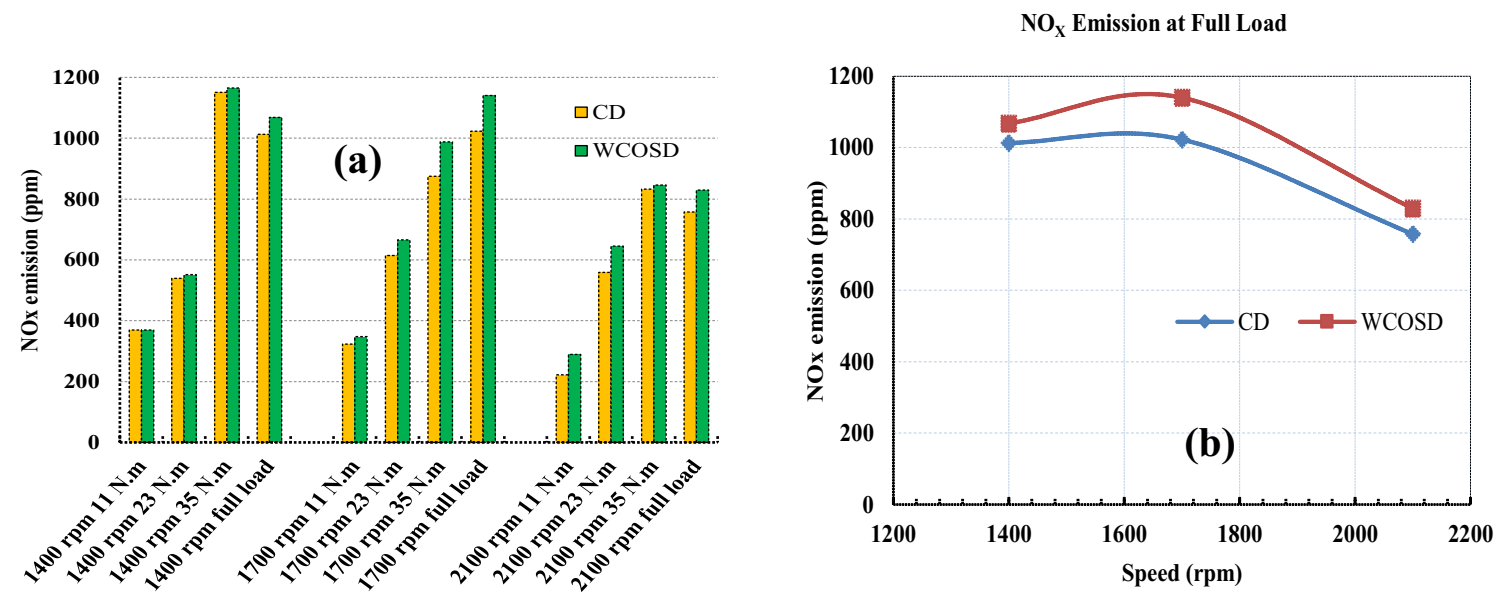

Fig. $8 \mathrm{NO}_{x}$ emissions of the test engine fueled CD and WOCSD at a $1400 \mathrm{rpm}, 1700 \mathrm{rpm}, 2100 \mathrm{rpm}$ and $\mathbf{b}$ full load
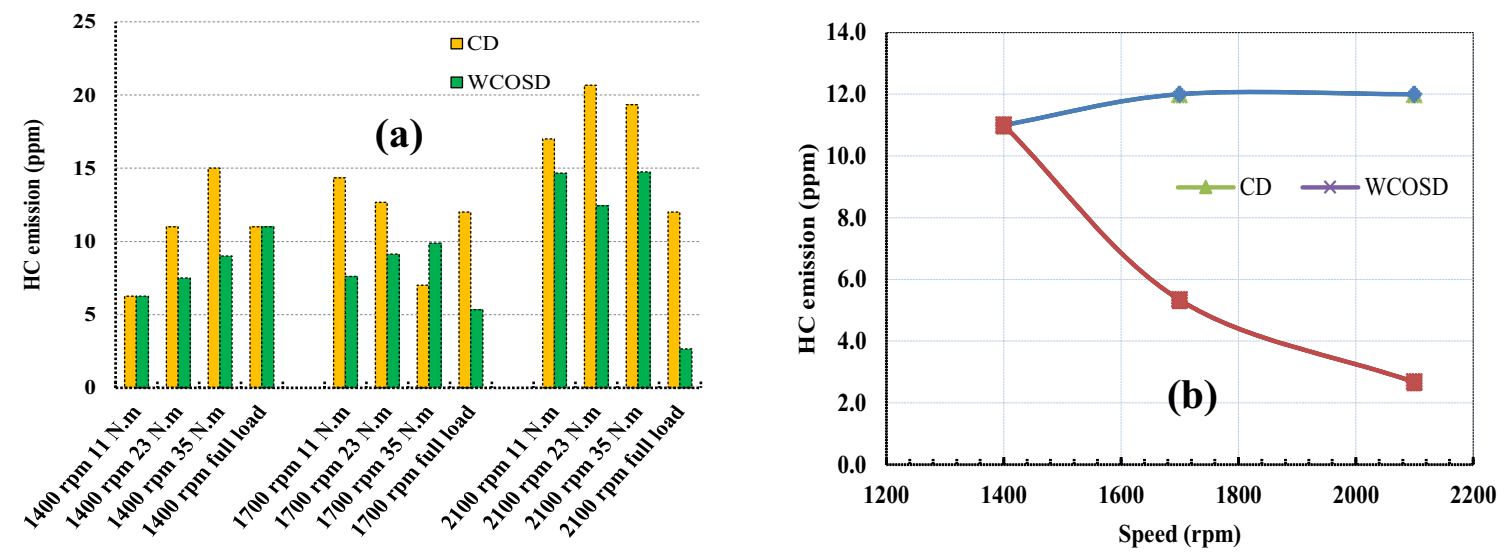

Fig. 9 Hydrocarbon emissions of the test engine fueled CD and WOCSD at a $1400 \mathrm{rpm}, 1700 \mathrm{rpm}, 2100 \mathrm{rpm}$ and b full load
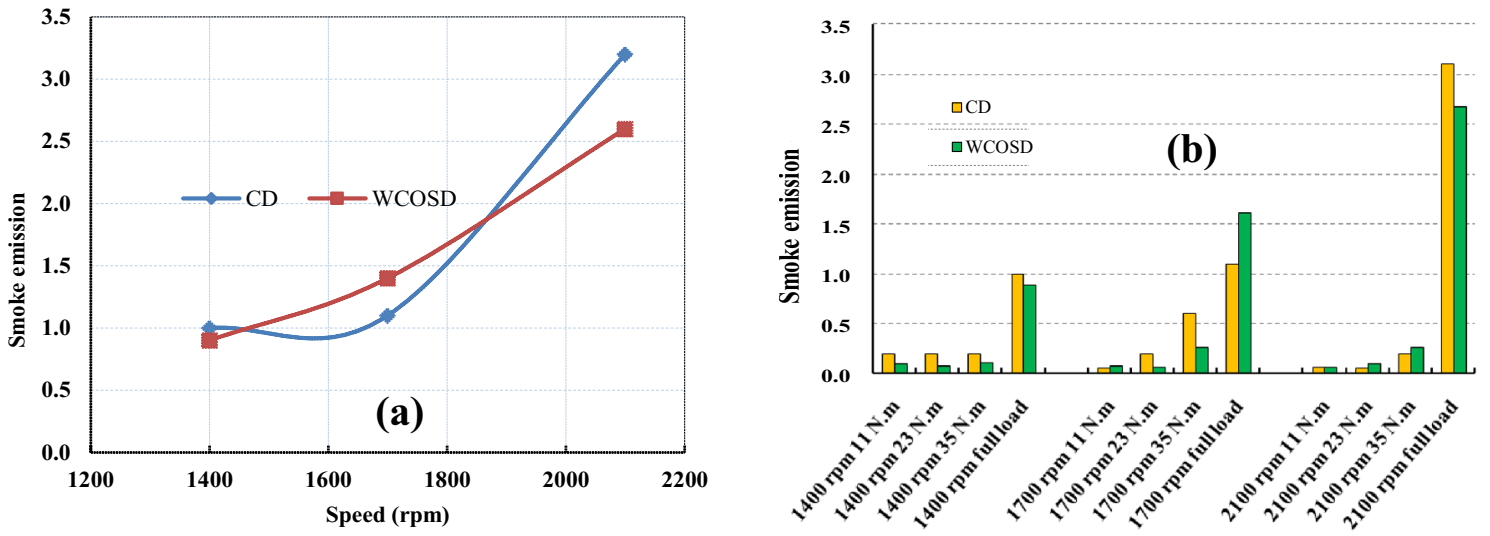

Fig. 10 Smoke emissions of the test engine fueled CD and WOCSD at a $1400 \mathrm{rpm}, 1700 \mathrm{rpm}, 2100 \mathrm{rpm}$ and $\mathbf{b}$ full load

\subsubsection{Comparison of smoke emissions}

Figure 10 presents the smoke emission experimental results of the test engine fueled WCOSD and CD. The trends of black smoke emissions from the engine fueled with both two tested fuels were similar. The smoke emissions were low at the low and medium loads and high at the full loads. The main reason for this phenomenon is that the mixtures at full load were substantially richer than these at low and medium loads, leading to the oxygen lack in the combustion process when the engine operated at full load conditions. Also, it can also be found that the average 
amount of black smoke emissions as the engine fueled with WCOSD was $17 \%$ lower than that with CD. At full load conditions, with both fuels, the smoke emissions from the engine increased the speed accordingly, as seen in Fig. 10b. This phenomenon can be explained that when the engine speed increased, the timings for fuel evaporation and mixing processes became shorter, which reduced the combustion quality.

\section{Conclusions}

In this paper, waste cooking oil synthetic diesel from waste cooking oil was produced by catalytic cracking in a batch reactor using $\mathrm{MgO}$ as a catalyst and used as investigated fuel. The engine fueled with WCOSD and CD to compare the engine characteristics, including engine power, fuel consumption, combustion process, and emissions. The results showed that the produced biodiesel is suitable in quality for running on diesel engines. Although the engine brake power of WCOSD slightly dropped at low and medium engine speed due to the lower of its heat value, it slightly increased at high engine speed since the ower viscosity of WCOSD enhanced air-fuel mixture formation in the combustion chamber. Furthermore, the BSFC of the test engine running on WCOSD increased at almost all engine operating conditions. In contrast, the in-cylinder pressure peaks in the engine running with WCOSD were lower than those of CD by $0.43,0.32$, and 0.74 bar at 11 , 23 , and $35 \mathrm{~N} \mathrm{~m}$, respectively. Besides, the emissions of nitrogen oxides of the test engine fueled WCOSD were higher than those of $\mathrm{CD}$ at all tested conditions. The hydrocarbon was lower for WCOSD in comparison to those of $\mathrm{CD}$ at almost all operating conditions. The $\mathrm{HC}$ emission of an engine fueled by WCOSD averagely reduced by $26.3 \%$. The smoke emission of the test engine in case of using WCOSD was 17\% lower on average than that of $\mathrm{CD}$. However, the carbon monoxide emissions were lower at the low and medium loads and higher at the full loads. For future research, we will focus to scale our system for commercial production as well as apply WCOSD for worldwide diesel vehicles.

\section{Compliance with ethical standards}

Conflict of interest The authors declare no conflict of interest regarding this research.

Open Access This article is licensed under a Creative Commons Attribution 4.0 International License, which permits use, sharing, adaptation, distribution and reproduction in any medium or format, as long as you give appropriate credit to the original author(s) and the source, provide a link to the Creative Commons licence, and indicate if changes were made. The images or other third party material in this article are included in the article's Creative Commons licence, unless indicated otherwise in a credit line to the material. If material is not included in the article's Creative Commons licence and your intended use is not permitted by statutory regulation or exceeds the permitted use, you will need to obtain permission directly from the copyright holder. To view a copy of this licence, visit http://creativecommons. org/licenses/by/4.0/.

\section{References}

Altin R, Çetinkaya S, Yücesu HS (2001) Potential of using vegetable oil fuels as fuel for diesel engines. Energy Convers Manag 42:529-538. https://doi.org/10.1016/S01968904(00)00080-7

Boggavarapu P, Ravikrishna R (2013) A review on atomization and sprays of biofuels for IC engine applications. Int J Spray Combust Dyn 5:85-121. https://doi.org/10.1260/1756-8277.5.2. 85

Buyukkaya E (2010) Effects of biodiesel on a di diesel engine performance, emission and combustion characteristics. Fuel 89:3099-3105. https://doi.org/10.1016/j.fuel.2010.05.034

Di Y, Cheung CS, Huang Z (2009) Experimental investigation on regulated and unregulated emissions of a diesel engine fueled with ultra-low sulfur diesel fuel blended with biodiesel from waste cooking oil. Sci Total Environ 407:835-846. https://doi. org/10.1016/j.scitotenv.2008.09.023

Fukuda H, Kondo A, Noda H (2001) Biodiesel fuel production by transesterification of oils. J Biosci Bioeng 92:405-416

Han X, You K, Tan J et al (2010) Characteristics of polycyclic aromatic hydrocarbons emissions of diesel engine fueled with biodiesel and diesel. Fuel 89:2040-2046. https://doi.org/10. 1016/j.fuel.2010.03.014

Hirkude JB, Padalkar AS (2012) Performance and emission analysis of a compression ignition. Engine operated on waste fried oil methyl esters. Appl Energy 90:68-72

Huang J, Wang Y, Qin J, Roskilly AP (2010) Comparative study of performance and emissions of a diesel engine using Chinese pistache and jatropha biodiesel. Fuel Process Technol 91:1761-1767

Kannan GR, Karvembu R, Anand R (2011) Effect of metal based additive on performance emission and combustion characteristics of diesel engine fuelled with biodiesel. Appl Energy 88:3694-3703. https://doi.org/10.1016/j.apenergy.2011.04.043

Macor A, Avella F, Faedo D (2011) Effects of 30\% v/v biodiesel/ diesel fuel blend on regulated and unregulated pollutant emissions from diesel engines. Appl Energy 88:4989-5001

Meng X, Chen G, Wang Y (2008) Biodiesel production from waste cooking oil via alkali catalyst and its engine test. Fuel Process Technol 89:851-857

Muralidharan K, Vasudevan D (2011) Performance, emission and combustion characteristics of a variable compression ratio engine using methyl esters of waste cooking oil and diesel blends. Appl Energy 88:3959-3968

Necati A, Canakci M (2010) The emission analysis of an IDI diesel engine fueled with methyl ester of waste frying palm oil and its blends. Biomass Bioenergy 34:1870-1878. https://doi.org/10. 1016/j.biombioe.2010.07.024

Necati A, Canakci M, Turkcan A, Sayin C (2009) Performance and combustion characteristics of a DI diesel engine fueled with waste palm oil and canola oil methyl esters. Fuel 88:629-636. https://doi.org/10.1016/j.fuel.2008.09.023

Qi DH, Geng LM, Chen H et al (2009) Combustion and performance evaluation of a diesel engine fueled with biodiesel produced from soybean crude oil. Renew Energy 34:2706-2713. https:// doi.org/10.1016/j.renene.2009.05.004 
Rajasekar E, Murugesan A, Subramanian R, Nedunchezhian N (2010) Review of $\mathrm{NO}_{x}$ reduction technologies in CI engines fuelled with oxygenated biomass fuels. Renew Sustain Energy Rev 14:2113-2121

Saravanan S, Nagarajan G, Lakshmi Narayana Rao G, Sampath S (2010) Combustion characteristics of a stationary diesel engine fuelled with a blend of crude rice bran oil methyl ester and diesel. Energy 35:94-100. https://doi.org/10.1016/j.energy.2009. 08.029

Sayin C, Canakci M (2009) Effects of injection timing on the engine performance and exhaust emissions of a dual-fuel diesel engine. Energy Convers Manag 50:203-213
Tesfa B, Mishra R, Zhang C et al (2013) Combustion and performance characteristics of $\mathrm{CI}$ (compression ignition) engine running with biodiesel. Energy 51:101-115. https://doi.org/10. 1016/j.energy.2013.01.010

Wako FM, Reshad AS, Bhalerao MS, Goud VV (2018) Catalytic cracking of waste cooking oil for biofuel production using zirconium oxide catalyst. Ind Crops Prod 118:282-289. https:// doi.org/10.1016/j.indcrop.2018.03.057

Zhu L, Cheung CS, Zhang WG, Huang Z (2011) Combustion, performance and emission characteristics of a di diesel engine fueled with ethanol-biodiesel blends. Fuel 90:1743-1750 